\title{
Daylight saving time and complications during cataract surgery
}

\author{
Richard H. C. Zegers ${ }^{1,2} \cdot$ Claudia C. Orelio ${ }^{3}$
}

Received: 28 August 2019 / Accepted: 12 September 2019 / Published online: 25 September 2019

(c) The Royal College of Ophthalmologists 2019

\section{To the Editor:}

In most European countries the transition to daylight saving time (DST) is formalised on the last Sunday of March by setting the clock $1 \mathrm{~h}$ forward. Some studies have associated the resulting hour of sleep deprivation with an increased occurrence of traffic accidents [1,2], workplace injuries [2], suicides [3], and even trampoline-related injuries [4]. We were wondering whether this transition of time could have an effect on the rate of complications during phacoemulsification cataract surgery.

In the Dutch cataract complication registration (DCCR) database Dutch ophthalmologists are able to voluntarily register their pre-, per-, and post-operative cataract extraction results, including any surgery-related complications. Registration is anonymous and it offers the possibility to compare one's own individual results to those of the peer group. We collected data from the DCCR database on phacoemulsification cataract operations over a 10-year period (2009-2018). Both the amount as well as types of intraoperative complications were collected for all registered phacoemulsification cataract operations (under topical as well as general anaesthesia) following the first week (W0) after change to DST; 1 (W - 1), $2(\mathrm{~W}-2)$, and $3(\mathrm{~W}-3)$ weeks before $\mathrm{W} 0$; and $1(\mathrm{~W}+1), 2(\mathrm{~W}+2)$, and $3(\mathrm{~W}+3)$ weeks after W0. Descriptive statistics and $2 \times 2$ contingency table Chi square testing was performed with SPSS 23.

Richard H. C. Zegers

r.h.zegers@gmail.com

1 Department of Ophthalmology, Diakonessenhuis, Utrecht/ Zeist, The Netherlands

2 Department of Ophthalmology, Amsterdam UMC, location AMC, Amsterdam, The Netherlands

3 Research Support, Diakademie, Diakonessenhuis, Utrecht/ Zeist, The Netherlands
Compared with the 3 weeks before ( $\mathrm{W}-3$ to $\mathrm{W}-1$ ) and after $(\mathrm{W}+1$ to $\mathrm{W}+3)$, the percentage of complications was not statistically different from the week (W0) following the transition to DST (Table 1). Also, comparing percentages of complications of $\mathrm{W}-1$ to $\mathrm{W} 0$ or $\mathrm{W} 0$ to $\mathrm{W}+1$ by Chi square testing did not reveal a significant difference $(P>0.1)$.

It should be noted that not all Dutch ophthalmologists participate in DCCR: in 2009 about 56\% of all Dutch cataract operations were included; in 2013 this was roughly $71 \%$; and in 2017 the score was $~ 95 \%$. Furthermore, there is no guarantee that all complications are reported or that all complications are registered correctly into the database. Another flaw that can influence our findings is the coincidence that the annual meeting of the Dutch Ophthalmological Society (DOS) frequently takes place in the last week of March, just the week before the transition to DST. During W -1 , nationwide a considerably lower amount of cataract operations is performed. For the study period, the congress and $\mathrm{W}-1$ overlapped in exactly $50 \%$ of cases in $2009,2010,2014,2015$, and 2018. Nevertheless, analysis demonstrated that there were no more and no less complications in these 5 years compared with the 5 years the annual DOS meeting was held in another week (three times in W0, once in $\mathrm{W}-2$ and once in $\mathrm{W}+1$ ).

The present study suggests that transition to DST has no effect on the occurrence of intraoperative complications during phacoemulsification. An additional finding is that the annual meeting of the DOS also seems to have no effect on the complication rate.

\section{Compliance with ethical standards}

Conflict of interest The authors declare that they have no conflict of interest.

Publisher's note Springer Nature remains neutral with regard to jurisdictional claims in published maps and institutional affiliations. 
Table 1 Percentages of all complications and more specifically the most serious complications in the week (W0) following transition to DST, 3 weeks ( $\mathrm{W}-3$ to $\mathrm{W}-1)$ before $\mathrm{W} 0$ and 3 weeks $(\mathrm{W}+1$ to $\mathrm{W}+3$ ) after $\mathrm{W} 0$ for the period 2009-2018

\begin{tabular}{lllll}
\hline & $\begin{array}{l}\text { All complications } \\
\text { (IQR) }\end{array}$ & $\begin{array}{l}\text { Posterior capsular } \\
\text { rupture without } \\
\text { vitreous loss }\end{array}$ & $\begin{array}{l}\text { Posterior capsular } \\
\text { rupture with } \\
\text { vitreous loss }\end{array}$ & Dropped nucleus \\
\hline Week -3 & $1.56(1.35-1.81)$ & $0.34(0.26-0.44)$ & $0.27(0.16-0.44)$ & $0.02(0.00-0.10)$ \\
Week -2 & $1.46(1.13-2.02)$ & $0.24(0.16-0.33)$ & $0.27(0.19-0.37)$ & $0.06(0.04-0.10)$ \\
Week -1 & $1.73(1.25-1.82)$ & $0.28(0.19-0.41)$ & $0.26(0.22-0.39)$ & $0.04(0.00-0.08)$ \\
Week 0 & $1.74(1.45-1.86)$ & $0.27(0.18-0.46)$ & $0.30(0.18-0.39)$ & $0.06(0.00-0.07)$ \\
Week +1 & $1.54(1.33-2.03)$ & $0.38(0.15-0.45)$ & $0.23(0.17-0.30)$ & $0.02(0.00-0.08)$ \\
Week +2 & $1.48(1.13-1.91)$ & $0.30(0.16-0.40)$ & $0.19(0.17-0.29)$ & $0.04(0.00-0.06)$ \\
Week +3 & $1.63(1.41-1.98)$ & $0.28(0.18-0.53)$ & $0.27(0.23-0.42)$ & $0.02(0.00-0.08)$ \\
\hline
\end{tabular}

The percentage was calculated by dividing the amount of complications by the total number of operations performed that week. Median percentage and interquartile range (IQR) are given. The mean amount of operations performed ranged from 2125 to 2369 operations per week

\section{References}

1. Varughese J, Allen RP. Fatal accidents following changes in daylight savings time: the American experience. Sleep Med. 2001;2:31-36.

2. Robb D, Barnes T. Accident rates and the impact of daylight saving time transitions. Accid Anal Prev. 2018;111:193-201.
3. Lindenberger LM, Ackermann H, Parzeller M. The controversial debate about daylight saving time (DST)-results of a retrospective forensic autopsy study in Frankfurt/Main (Germany) over 10 years (2006-2015). Int J Legal Med. 2018. https://doi.org/10.1007/ s00414-018-1960-z

4. Yule MS, Krishna S, Rahiri JL, Hill AG. Trampoline-associated injuries are more common in children in spring. $\mathrm{N} \mathrm{Z} \mathrm{Med} \mathrm{J.}$ 2016;129:38-43. 